\title{
DIE INVLOED VAN NATE OP DIE LOOP VAN DIE ORANJERIVIER IN DIE OMGEWING VAN DIE AUGRABIESWATERVAL NASIONALE PARK
}

\author{
M. J. SLABBERT en S. J. MALHERBE
}

\section{Geologiese Opname}

Posbus 775

Upington

8800

Samevatting - Twee duidelike, bykans vertikale noord- en ooswaartsneigende natstelsels is goed ontwikkel dwarsdeur die Augrabieswaterval Nasionale Park. Die twee hoofvloeirigtings van die rivier stem ooreen met die oriëntasie van die naatstelsels. Die tralievormige vloeipatroon van die rivier kan hiervolgens verklaar word. Hierdie nate tesame met ondergeskikte nate en verskuiwings kan ook sekere geomorfologiese verskynsels in die park verklaar.

Abstract - Two distinct, near-vertical, north- and east-trending joint sets are well developed throughout the Augrabies Falls National Park. The two main flow directions of the river are in accordance to the orientation of these joints. The lattice-type flow pattern of the river can therefore be explained by their influence. These joints together with subordinate joints and faults could explain some of the geomorphological features within the park.

\section{Inleiding}

Die loop van die Oranjerivier onderkant die Augrabieswaterval in die Augrabieswaterval Nasionale Park, Republiek van Suid-Afrika, besit 'n tipiese tralievormige vloeipatroon. Deur'n studie van die naatstalsels is daar gepoog om te bepaal watter invloed dit op die ontwikkeling van die loop van die rivier het. King (1951) beweer dat die Augrabieswaterval rivierop teruggesny het gedurende sy Afrikasiklus van erosie. Later stel Wellington (1955) voor dat die kloof en waterval beheer word deur die hardheid van die rots en die helling en strekking van die foliasie in die gesteentes.

Onstabiliteit in die aardkors, wat op 'n verskeidenheid maniere kan ontstaan, lei daartoe dat spanning in gesteentes ontwikkel. Wanneer die spanning 'n kritiese punt oorskry, word dit ontlaai deur die ontwikkeling van nate en verskuiwings.

Nate in gesteentes word herken as nou gespasieërde parallelle breukvlakke waarlangs daar baie min verplasing voorkom en hul oriëntasie is direk afhanklik van die rigting waaruit die druk gerig was. Naatstelsels wat op dié manier ontstaan, 
word meesternate genoem en besit die eienskap dat hulle uit twee hoofstelle wat mekaar kruis, bestaan. Daarby ontwikkel ondergeskikte nate waarvan die oriëntasie nie dieselfde is as dié van die meesternate nie.

Naas nate is verskuiwings ook 'n manier waarop spanning ontlaai kan word. Verskuiwings verskil egter van nate deurdat die verplasings langs die breukvlakke groot is en gewoonlik as enkele linieêre strukture, wat oor etlike kilometers kan strek, voorkom. Die wydte kan van 'n paar sentimeters tot enkele meters varieer. Tydens die verskuiwingsproses word die gesteentes langs die verskuiwingsvlak fyn gemaal (gemilonitiseer) en gebreksieer. Hierdie materiaal kan deur verkitting verkleur en weerstandbiedend teen verwering wees.

In 'n geneisige terrein, soos by Augrabies, sny 'n rivier sy loop terug deur middel van stroomversnellings. Om ' $n$ vertikale val te vorm, is 'n versperring, waaroor die water kan stort, nodig. 'n Weerstandbiedende verskuiwing wat oor 'n terugkerwende rivier sny, kan as ' $n$ versperring dien. Die gedeelte aan die stroomaf kant van die verskuiwing word dieper ingekerf terwyl die gedeelte aan die stroomop kant ingekerf word teen die tempo van erosie van die versperring.

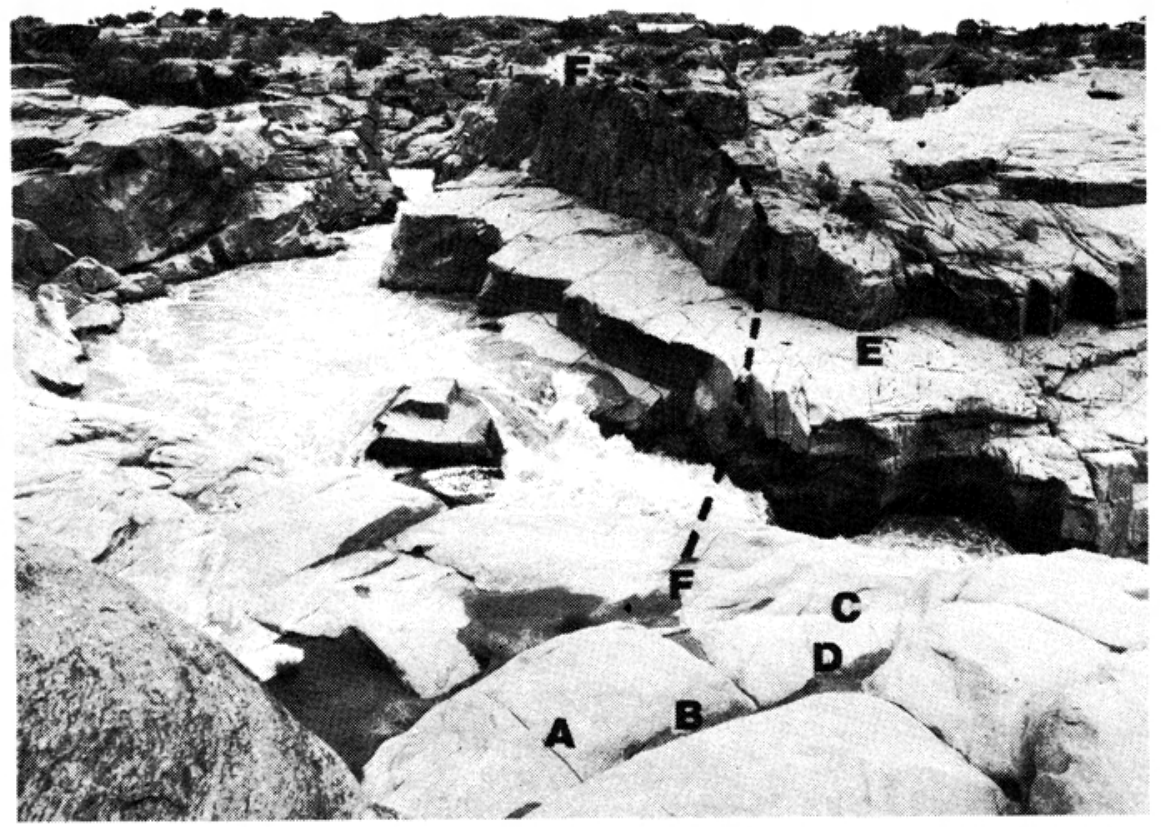

Fig. 1. Naatkontrole by die hoofval. Die nate wat herken kan word, is:

A - die noordgerigte meesternate.

$\mathrm{B}$ - die oosgerigte meesternate.

$\mathrm{C}$ - die noordwesgerigte ondergeskikte nate.

$\mathrm{D}$ - die noordoosgerigte ondergeskikte nate.

E - die horisontale ondergeskikte nate.

Die verskuiwingsone wat as ' $\mathrm{n}$ versperring dien, word deur $\mathrm{F}$ aangedui.

Foto M. D. Köhler 


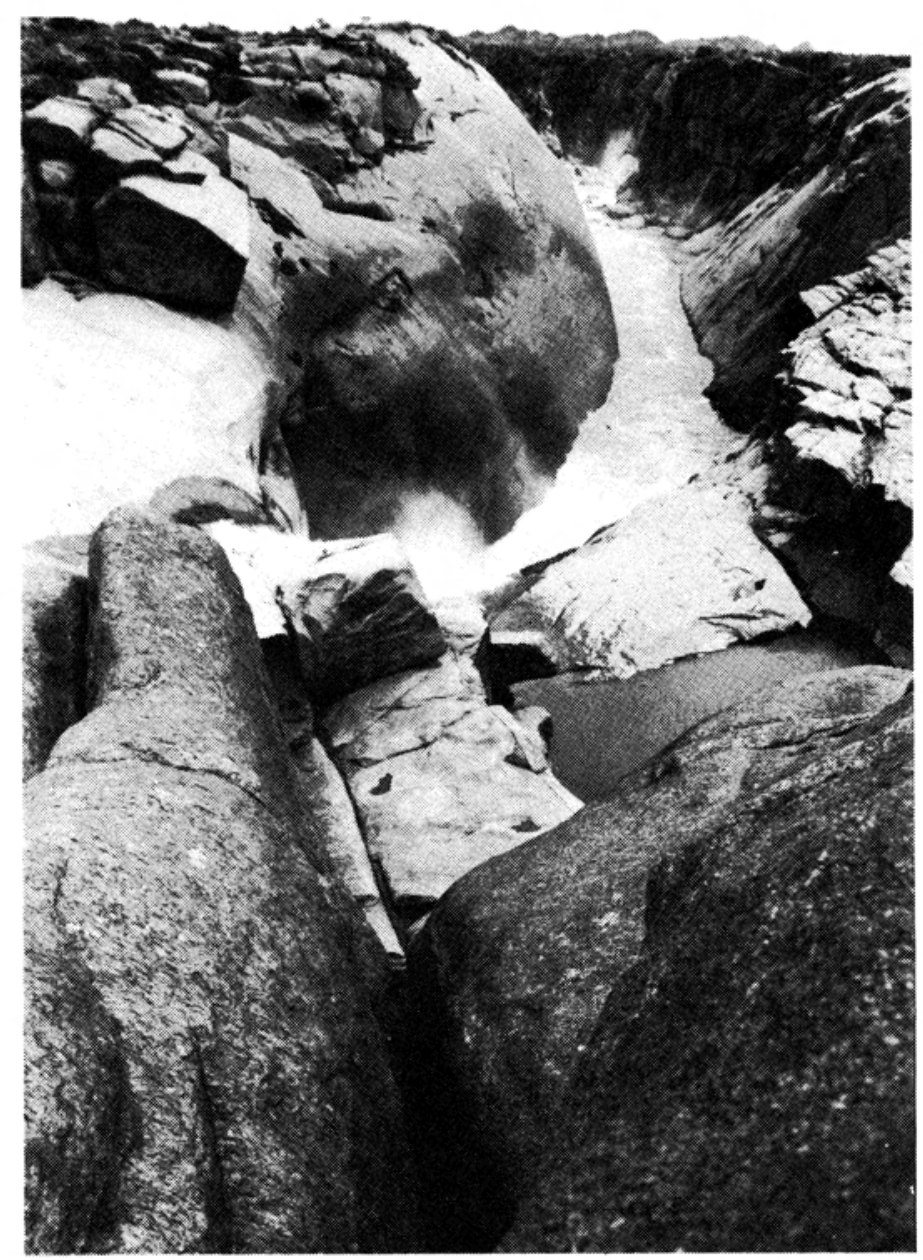

Fig. 2. Die insnyding van die rivier by die hoofval langs noord-wesgerigte nate.

Foto M. D. Köhler

Sowat 700 nate is in die park opgemeet en het die bestaan van twee prominent ontwikkelde meesternaatstelsels aan die lig gekom. Die strekking van die twee meesternaatstelsels is noord- en ooswaarts, terwyl hulle sterk vertikaal neig.

\section{Bespreking}

Die rivierloop volg meesal die meesternate (Fig. 1 en 2) wat deur die hele park aangetref word (Fig. 3) en verklaar die tralievormige vloeipatroon van die rivier in die omgewing van Eggohoek, Oranjekom en Ararat. Ondergeskikte nate kom algemeen voor en goeie voorbeelde kan in die wande van die ravyn gesien word as nate wat amper horisontaal lê (Fig. 1). Hulle het skynbaar nie 'n noemenswaardige invloed op die rivier se vloeipatroon in dié omgewing gehad nie. 


\section{LEGENDE}

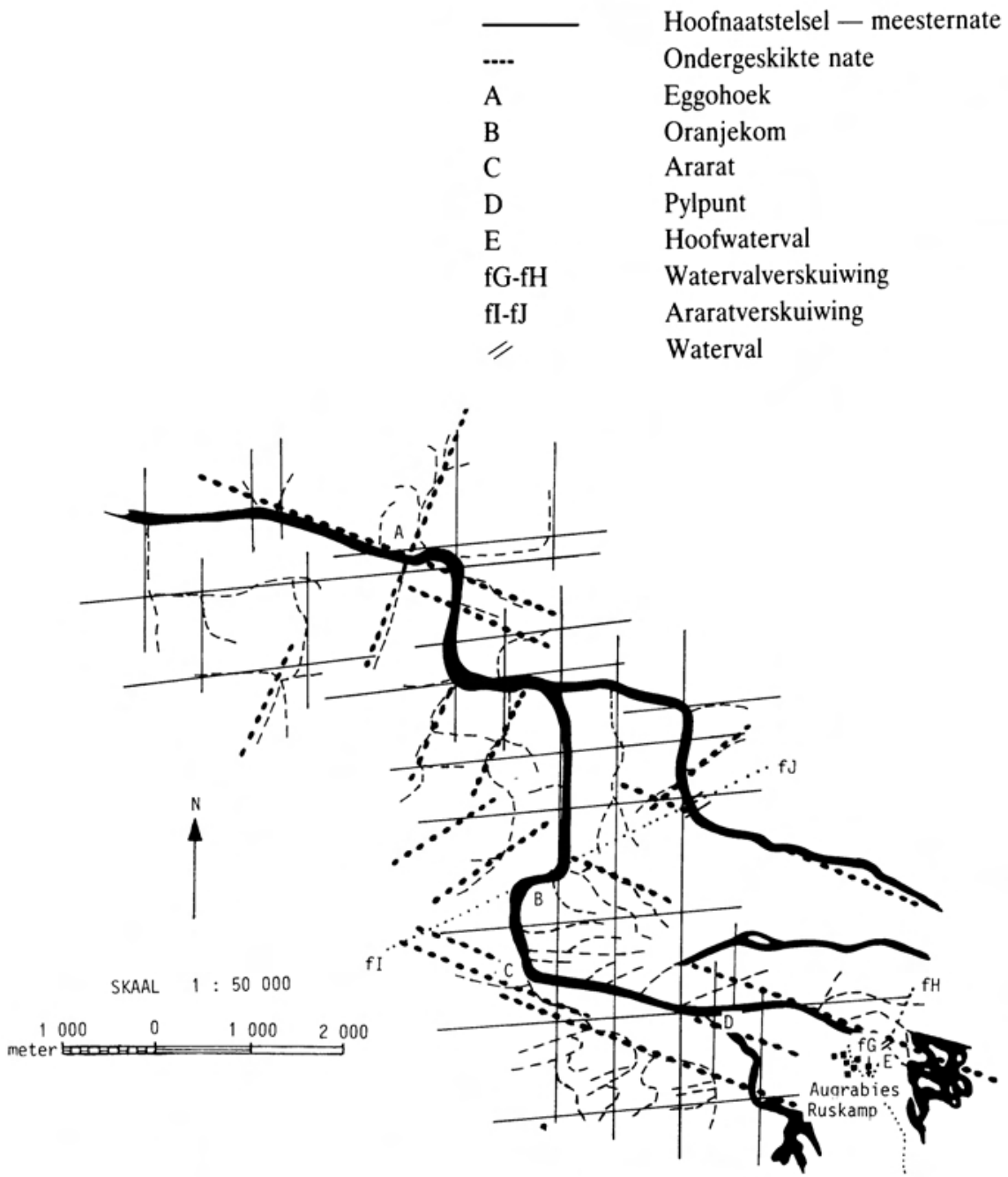

Fig. 3. Die loop van die Oranjerivier in verhouding tot die naatstelsels in die Augrabieswaterval Nasionale Park (Nate verkry vanaf lugfoto's).

Tussen Oranjekom en die hoofval vertoon die loop 'n ietwat geboë vorm (Fig. 2) wat verklaar kan word deur ondergeskikte vertikale nate (Fig. 1) wat waarskynlik 'n belangriker rol in dié omgewing gespeel het.

Naas die meesternate is 'n ondergeskikte stel (Fig. 1) wat ongeveer noord-wes strek en ook vertikaal neig, hier meer prominent ontwikkel. Die komplimentêre noordoosgerigte nate is teenwoordig (Fig. 1) maar is minder talryk. Die invloed van hierdie naatstel word skematies in Fig. 4 voorgestel. 


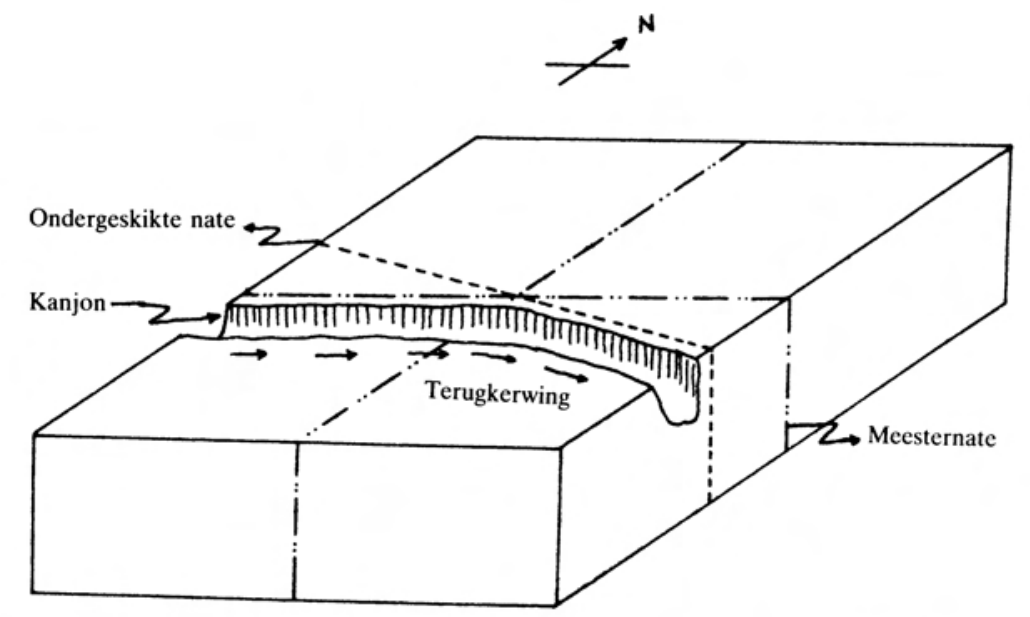

Fig. 4. 'n Skematiese voorstelling van die invloed van die ondergeskikte nate op die vloeirigting van die rivier in die oostelike deel van die Augrabieswaterval Nasionale Park.

Die Pylpunt wat in die omgewing voorkom, kan ook verklaar word deur die invloed van hierdie ondergeskikte naatstel (Fig. 5).

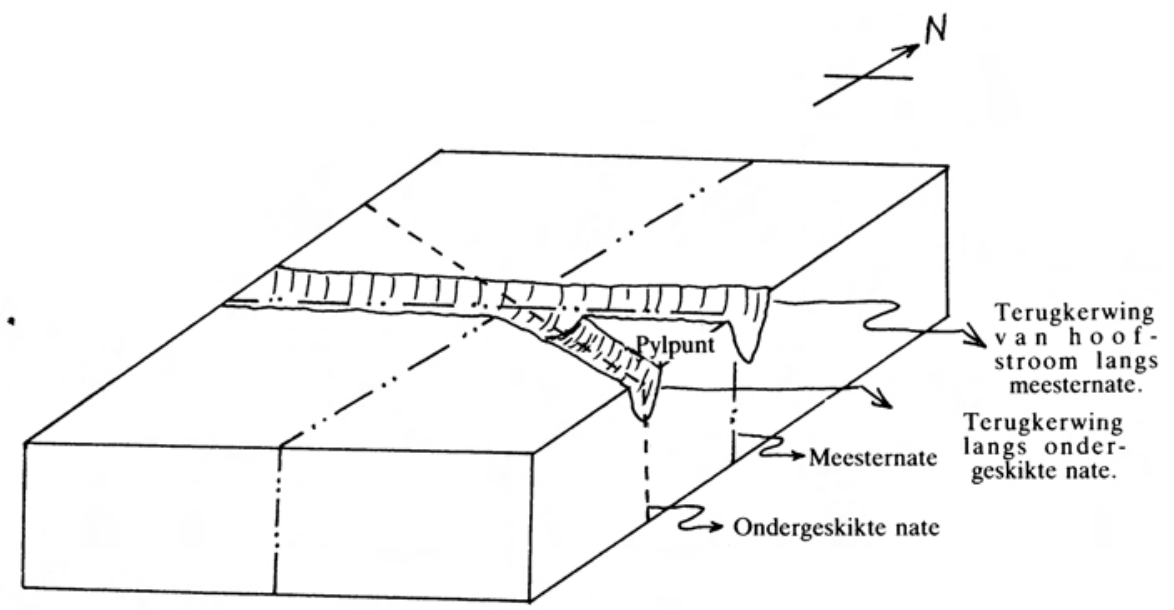

Fig. 5. 'n Skematiese voorstelling van die ontstaan van die Pylpunt deur inkerwing van die rivier langs die meester- en ondergeskikte nate. 


\section{Verskuiwings}

Twee verskuiwings of gemilonitiseerde sones, een in die omgewing van die hoofval (Watervalverskuiwing) (Fig. 1) en die ander in die omgewing van Ararat (Araratverskuiwing), kom in die park voor (Fig. 3). Die strekking van beide is ongeveer noordoos en het waarskynlik 'n invloed op die ontstaan van die waterval gehad.

Die systrome stroomaf vanaf die Araratverskuiwing is ingekerf tot op die huidige vlak van die Oranjerivier, terwyl die systrome stroomop as swewende watervalle voorkom (Fig. 6 en 7). Gevolglik kan daar gespekuleer word dat 'n ou waterval as gevolg van die Araratverskuiwing, wat as 'n versperring gedien het, kon bestaan het en dat die systrome aan die onderkant daarvan teen dieselfde tempo as die ravyn ingekerf het. Nadat die versperring by die Araratverskuiwing vernietig is, het die rivier vinnig teruggekerf tot waar die val tans voorkom met die Watervalverskuiwing as versperring. As gevolg van die vinnige terugkerwing kon die systrome se vertikale erosie nie die pas volhou nie en kom hulle as swewende watervalle voor. Stroomop van die waterval sny die rivier tans terug deur middel van stroomversnellings.

Klimaatsveranderings speel 'n groot bydraende rol in die inkerwingstempo van riviere en strome en het sekerlik ook hier 'n invloed gehad. Indien die reënval in die omgewing van die waterval sou afneem en die rivier nog baie water uit sy bolope afvoer, sal die rivier terugsny maar die sylope se vertikale erosietempo sal drasties afneem.

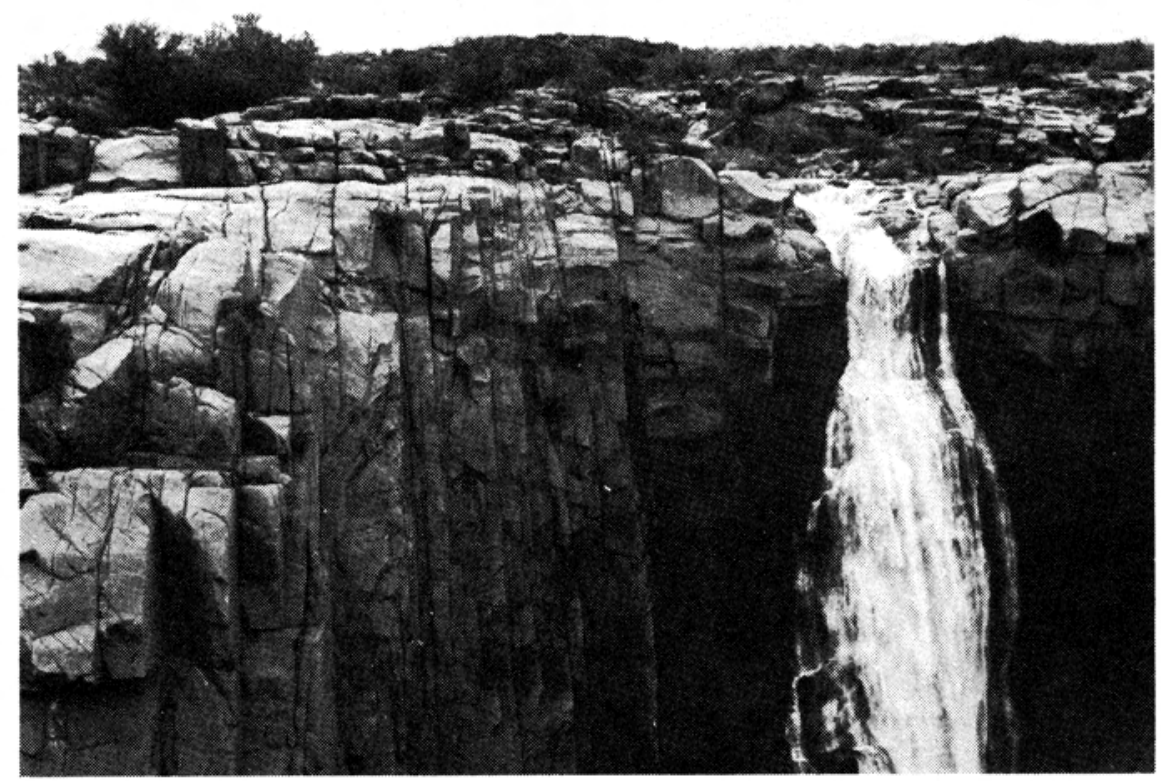

Fig. 6. Die Bruidsluierwaterval. 'n Swewende kloof wat terugsny langs die noordgerigte nate.

Foto M. D. Köhler 


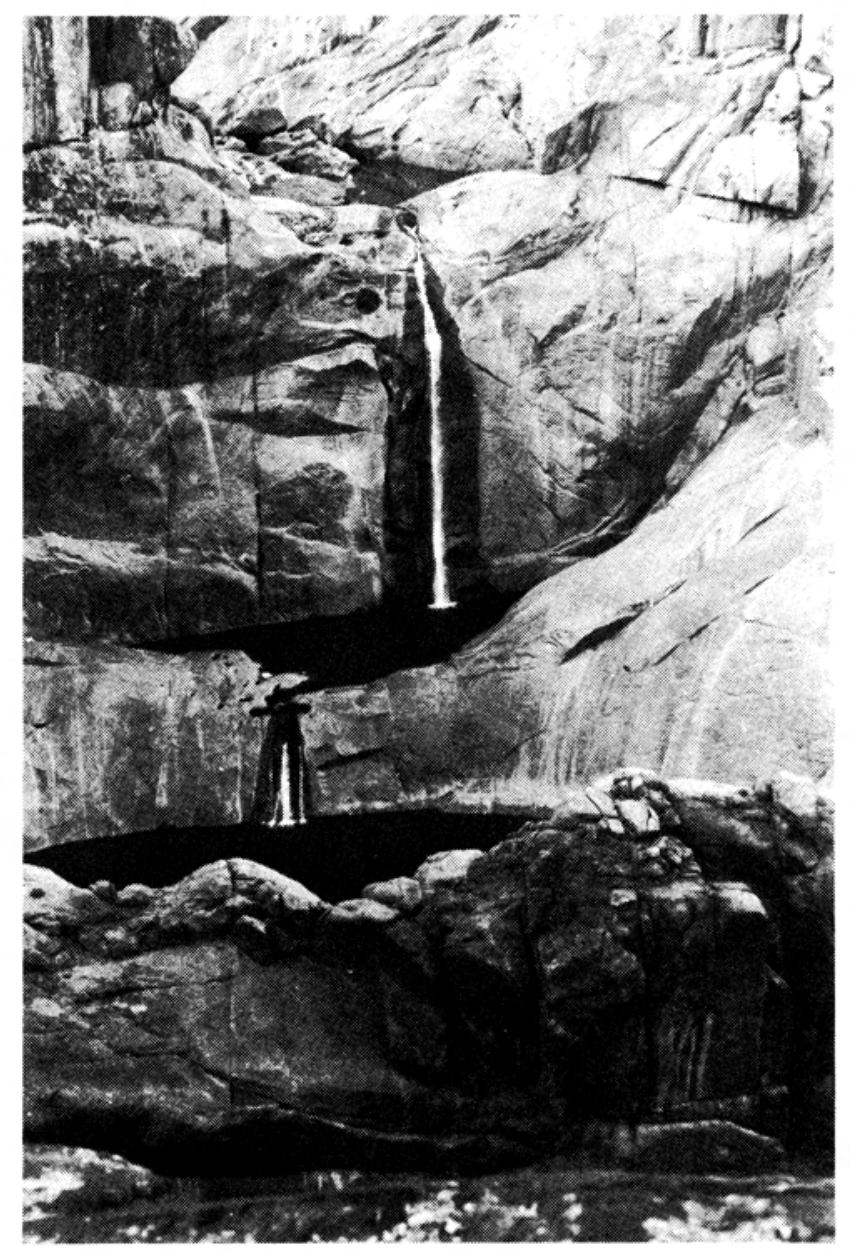

Fig. 7. Die Tweelingwaterval. 'n Swewende kloof wat deur noordgerigte nate beheer word.

Foto M. D. Köhler

\section{VERWYSINGS}

KING, L. C. 1951. South African Scenery - a Textbook of Geomorphology. London: Oliver and Boyd.

WEllingtON, J. H. 1955. Southern Africa - A Geographical Study. Vol. 1. London: Cambridge Univ. Press. 